\title{
PROTÓTIPO DE CANHÃO A EXPLOSÃO
}

\section{Márcio Eleotério Cunha1, Marcelo Birello March², Gabriel Bandartchuc ${ }^{3}$, Beatriz Farinacio Camillo4}

\author{
${ }^{1}$ Docente da oficina de Física, NAAH/S - Núcleo de Atividades de Altas Habilidades/Superdotação-Londrina. \\ marcioecunha1@gmail.com \\ ${ }^{2}$ Docente, Coordenador, NAAH/S - Núcleo de Atividades de Altas Habilidades/Superdotação-Londrina. \\ mbirello@gmail.com \\ ${ }^{3}$ Discente, NAAH/S - Núcleo de Atividades de Altas Habilidades/Superdotação-Londrina \\ gabrielbtchuc@gmail.com.br \\ ${ }^{4}$ Discente, NAAH/S - Núcleo de Atividades de Altas Habilidades/Superdotação-Londrina.
} lancador100@gmail.com

\begin{abstract}
RESUMO:
O ensino de Física tem como desafio atrair a atenção dos estudantes. Muitos conteúdos necessitam transcender as teorias em sala de aula, de modo a visualizar os fenômenos para sua melhor compreensão. Neste trabalho utilizou-se as metodologias ativas (MA) de ensino aprendizagem, com objetivo de facilitar o estudo e a compreensão da Física, e, incentivar o estudante a apropriar-se desta ferramenta e promover sólida formação tecnológica, especificamente nos conteúdos de termodinâmica e cinemática: velocidade; movimento uniforme; movimento uniformemente variado; movimento vertical; vetores e movimento oblíquo, por meio da construção experimental de um protótipo de canhão a explosão. Tal projeto justifica-se por facilitar a aplicação da teoria com a prática, onde estudantes do ensino fundamental II antecipam o contato dos conteúdos de Física de forma criativa, interativa, didática e lúdica. Na construção do projeto foram utilizados os materiais de baixo custo como madeira reutilizada, fio de telefone, clique de isqueiro, tubo de filme de máquina fotográfica, parafusos de rosca, argolas de metais, álcool de carro(combustível) e parafuso borboleta. Após a construção do experimento, verificou-se que a explosão do projétil (tubo de filme de máquina fotográfica) descreva um arco de parábola, que permita estudar algumas variáveis, dentre elas, a velocidade e alcance máximo devido ao ângulo de lançamento, bem como a ignição da explosão. De acordo com o cronograma haverá estudo dos conceitos de termodinâmica e cinemática, uma vez que no ensino fundamental II ainda não tem em sua grade curricular esses conteúdos, e quando os tem, são vistos superficialmente.
\end{abstract}

Palavras-chave: Ensino de Física; Ensino de química; interdisciplinaridade; Metodologia ativa.

\section{INTRODUÇÃO}

O ensino de Física tem como desafio atrair a atenção dos estudantes. Muitos conteúdos necessitam transcender as teorias em sala de aula, de modo a visualizar os fenômenos para sua melhor compreensão.

Por definição, segundo (HALLIDAY; RESNICK; WALKER, 2007.p70), "um projétil é uma partícula que se move em um plano vertical com velocidade inicial $\overrightarrow{V_{0}}$ e com uma aceleração constante, igual a aceleração de queda livre $g$, dirigida para baixo". $O$ movimento de projéteis é uma forma de movimento na qual um objeto ou partícula (chamados de projétil) é arremessado próximo a superfície da terra e se move ao longo de um caminho curvilíneo, sob influência apenas da ação da gravidade (desprezando a resistência do ar), ou seja, a única força significante que atua no objeto é a força da gravidade, na qual atua de cima para baixo, causando uma aceleração em direção ao solo. A definição acima pode parecer confusa para um estudante de física iniciante sem uma demonstração prática do seu significado.

O Protótipo de Canhão a Explosão (PCE) é um experimento didático construído com materiais de baixo custo que permite ilustrar a transformação da energia entre diferentes modalidades, desde a forma química até a mecânica cinética e potencial (Gref, 2002). 
projétil é feito de um simples tubo de plástico de filme de $35 \mathrm{~mm}$. Para o seu lançamento o mesmo é preenchido com um pequeno volume de combustível pulverizado na presença de ar. Após carregado com combustível é acionada uma faísca - tendo como origem um ignitor piezelétrico (obtido a partir de simples isqueiros industrializados) - e com isso observa-se a explosão em que parte da energia se transfere para o lançamento do projétil, devido ao posicionamento adequado deste em uma base lançadora (Teixeira; Ramos; Cruz, 2006).

No processo de ensino e aprendizagem professor e aluno devem estar em sincronia. Para que essa sincronia aconteça o professor busca ferramentas que desperte no aluno a vontade de envolver-se e motivar-se com o conteúdo a ser estudado. Nesse trabalho foi usado a prática de aprendizagem ativa, onde o aluno não é mero expectador mas participa ativamente da construção do conhecimento.

\section{MATERIAIS E MÉTODOS}

Este estudo trata-se de um relato de experiência do NAAH/S (Núcleos de Atividades de Altas Habilidades/ Superdotação) de Londrina, referentes a disciplina de Física, a utilizar metodologias ativas (MA) no processo de ensino aprendizagem (Bergmann; Sams, 2016; Buss; Mackedanz, 2017). O protótipo didático e seu estudo trazem em si oportunidades para o ensino de conceitos de química, física e formação, inter-relacionados em discussão de disciplinas nas quais mecânica clássica, termoquímica e termodinâmica encontram-se presentes.

Com o PCE é possível estudar princípios básicos mecânica clássica e dos processos termodinâmicos, sua fundamentação na construção das máquinas térmicas, bem como o processo histórico da evolução conceitual associado ao desenvolvimento tecnológico. Didaticamente o trabalho se desenvolve por meio de oficinas. Inicialmente apresenta-se aos aprendizes uma demonstração de funcionamento do PCE, cujo lançamento balístico do projétil (compreendendo a trajetória em forma de parábola) e estampido da combustão costumam provocar bastante euforia e interesse (Monteiro, 2016).

Após esta etapa oferecesse aos sujeitos a oportunidade de manusear o protótipo, fazendo alguns lançamentos, e, por fim, a discussão teórica, a construção de um protótipo e medidas experimentais. A montagem do dispositivo é feita com a utilização de um kit. Nesta fase os aprendizes enfrentam as dificuldades inerentes ao processo de construção e elaboração das necessidades para o perfeito funcionamento do protótipo. Uma vez tendo cada equipe seu protótipo, segue-se a medida dos lançamentos, através das quais, após tabulação serão comparadas com a previsão original teórica, permitindo o cálculo final do rendimento do protótipo (Teixeira; Ramos; Cruz, 2006).

A experiência teve início no ano de 2019 com a participação de dois alunos. A organização das atividades utilizando a MA ocorreu da seguinte forma:

- Na construção do projeto foram utilizados os materiais de baixo custo como madeira reutilizada, fio de telefone, clique de isqueiro, tubo de filme de máquina fotográfica, parafusos de rosca, argolas de metais, álcool de carro(combustível) e parafuso borboleta. Após a construção do experimento, verificou-se que a explosão do projétil (tubo de filme de máquina fotográfica) descreva um arco de parábola, que permita estudar algumas variáveis, dentre elas, a velocidade e alcance máximo devido ao ângulo de lançamento, bem como a ignição da explosão.

- Todos materiais foram confeccionados com ferramentas, martelo, serrote, furadeira, chave de fenda, alicate, sempre com supervisão de um docente orientador. 


\section{RESULTADOS E DISCUSSÕES}

O trabalho com o PCE já foi desenvolvido em vários níveis do processo educacional, com alunos da graduação de Física, ensino médio e fundamental II. Os resultados de aprendizagem variam de acordo com o nível em que se é aplicado a atividade, embora tenhamos observado que o envolvimento didático, motivação e encantamento sejam semelhantes em todas as faixas etárias estudadas.

No caso de alunos do ensino médio e do ensino fundamental II a dificuldade apresentada para o cálculo dos valores teóricos requer do professor uma presença mais marcante. No entanto após a realização do experimento, nota-se que os conceitos primários estão bem assentados em função da discussão qualitativa que segue a atividade experimental.

No caso de alunos do ensino superior e professores de Educação Básica a discussão posterior ganha um caráter importante de formação e de aprofundamento das questões de ensino envolvendo a temática termodinâmica e mecânica clássica. $E$, com isso, a atividade acaba por alcançar objetivos mais amplos que o simples cálculo de se rendimento termodinâmico, estudos da mecânica clássica e discutindo a formação para lidar com esses conceitos e as possibilidades experimentais didáticas.

\section{CONSIDERAÇÕES FINAIS}

Em todos os níveis de ensino estudados percebe-se grande dificuldade inicial dos aprendizes em lidar com conceitos e cálculos termodinâmicos. A atividade experimental e a oficina de construção do protótipo de canhão a explosão mostraram-se capazes de, a partir de materiais de baixo custo, aprofundar os conceitos elementares de termodinâmica, como também oferecer oportunidades de resgatar inter-relações entre disciplinas que normalmente apresentam essa temática de maneira estanque e compartimentalizada.

$\mathrm{Na}$ discussão teórica os aprendizes aproximam-se dos conceitos de termoquímica e termodinâmica, tais como nomenclatura de compostos orgânicos, equacionamento de uma reação de combustão, entalpia de formação das substâncias, variação de entalpia no processo de queima do combustível, cálculo de reagente em excesso, transformação de unidades, determinação de área e volume de estruturas geométricas, transformações de unidades de grandezas (densidade, massa molar, teor alcoólico, volume molar dos gases), transformação entre modalidades de energia (particularmente a equivalência mecânica da energia térmica) e determinação de sua eficácia.

A ludicidade do PCE e sua simplicidade de construção mostraram-se elementos essenciais para o trabalho didático com a Termodinâmica. Os resultados didáticos do uso do PCE mostraram-se bastante promissores em termos de formação básica bem como no aprofundamento de estudos teóricos de alunos de nível superior e professores em formação continuada.

\section{REFERÊNCIAS}

BERGMANN, Jon.; SAMS, Aaron. Sala de aula invertida - uma metodologia ativa de aprendizagem. 1. ed. Rio de Janeiro, 2016.

BUSS, Cristiano; MACKEDANZ, Luiz. O ensino através de projetos como metodologia ativa de ensino e de aprendizagem. Revista Thema, [s.I.], v. 14, n. 3, p.122-131, 5 ago. 2017. Instituto Federal de Educacao, Ciencia e Tecnologia Sul-RioGrandense 
Grupo de Reelaboração do Ensino de Física - GREF. (2002). Física 1: Mecânica. 7. ed. São Paulo: Edusp.

Grupo de Reelaboração do Ensino de Física - GREF. (2002). Física 2: Física Térmica e Óptica. 5. ed. São Paulo: Edusp.

HALLIDAY, D.; RESNICK, R. ; WALKER, J. Fundamentos de física volume 1. $8^{\text {a }}$ edição. Rio de Janeiro: LTC Livros Tecnicos e Científicos Editora S.A. 2009. 349p

MONTEIRO, Marco Aurélio. (2016) O uso de tecnologias móveis no ensino de física: uma avaliação de seu impacto sobre a aprendizagem dos alunos. Revista Brasileira de Pesquisa em Educação em Ciências, v.16, n.1, 2016. Disponível em: https://periodicos.ufmg.br/index.php/rbpec/article/view/4334/2900. Acesso em : 25 de jul. 2019.

TEIXEIRA, Marcelo Eduardo Fonseca; RAMOS, Maria de França; CRUZ, Blasi. Lançador de projéteis: a termodinâmica numa perspectiva interdisciplinar. Sociedade Brasileira para o Progresso da Ciência - SBPC, 2006. Disponível em: http://www.sbpcnet.org.br/livro/58ra/SENIOR/RESUMOS/resumo_3512.html. Acesso em: 20 de julho de 2019. 